\title{
Insecticide Resistance and Detoxification Enzymes Activity in Nilaparvata lugens Stål Against Neonicotinoids
}

\author{
Muhammad Musa Khan ${ }^{1}$, Rana Muhammad Kaleem-Ullah ${ }^{2}$ \& Junaid Ali Siddiqui ${ }^{3}$ \& Shahbaz Ali ${ }^{4}$ \\ ${ }^{1}$ Key Laboratory of Bio-Pesticide Innovation and Application, Engineering Research Centre of Biological Control, \\ South China Agricultural University, Guangzhou, China \\ ${ }^{2}$ Hubei Insect Resources Utilization and Sustainable Pest Management Key Laboratory, College of Plant Science \\ and Technology, Huazhong Agricultural University, Wuhan, China \\ ${ }^{3}$ Red Imported Fire Ant Research Center, South China Agriculture University, Guangzhou, China \\ ${ }^{4}$ Department of Plant Protection, Ghazi University, Dera Ghazi Khan, Pakistan \\ Correspondence: Muhammad Musa Khan, Key Laboratory of Bio-Pesticide Innovation and Application, \\ Engineering Research Centre of Biological Control, South China Agricultural University, 510642 Guangzhou, \\ China. Tel: 86-139-7120-8390.E-mail: drmusakhan@outlook.com
}

Received: February 24, $2020 \quad$ Accepted: March 27, $2020 \quad$ Online Published: April 15, 2020

doi:10.5539/jas.v12n5p24 URL: https://doi.org/10.5539/jas.v12n5p24

\begin{abstract}
The Nilaparvata lugens (Stål) is one of the most destructive pests of rice crops in Asian. To assess the resistance of imidacloprid, thiamethoxam, clothianidin, and nitenpyram, $N$. lugens exposed to each pesticide up to 15 generations. Results showed that the resistance of $N$. lugens increased significantly against imidacloprid, thiamethoxam, clothianidin, and nitenpyram (neonicotinoids) under selection pressure. There was a 118.07-fold increase in resistance against imidacloprid, 90.37-fold against thiamethoxam, 217.81-fold against clothianidin, and 34.09-fold against nitenpyram in $15^{\text {th }}$ generation as compared to $\mathrm{F}_{0}$. Based on fold increase, imidacloprid and clothianidin subjected for enzymatic analysis and results showed that enzyme activity involves resistance development against neonicotinoids. Cytochrome P450, esterase, and GST had significantly higher activity as the generation passes under the selection pressure of imidacloprid and clothianidin. There was a significant correlation existed between GST, and esterase activity, when compared to $\mathrm{LC}_{50}$ of imidacloprid. GST, esterase and P450 showed a significant correlation with $\mathrm{LC}_{50}$ of clothianidin. The results showed that detoxification enzymes play an important role in insecticide detoxification. When the mixture of imidacloprid and clothianidin tested results showed that the mortality exerted was similar to control when imidacloprid and clothianidin resistant populations were exposed.
\end{abstract}

Keywords: Nilaparavata lugens, neonicotinoids, selection pressure, detoxification enzyme activity, resistance ratio, antagonism

\section{Introduction}

The brown planthopper (Nilaparvata lugens) is an important and notorious pest in rice agroecosystem in many parts of Asia. N. lugens is a monophagous insect pest, which feeds only on rice (O. sativa) or wild rice species. Moreover, this pest is a destructive cropland insect pest in temperate parts of Asia, especially frequently erupting in China (Wang et al., 2008; Y. Wang \& M. Wang, 2007). It causes hopper burn and other direct damages on rice crops by sucking from the phloem and transmitting plant viral diseases, including the Rice Grassy Stunt Virus (RGSV) and Rice Ragged Stunt Virus (RRSV) to the rice plant (Maholidy, 2019).

During the 1950s, DDT (dichlorodiphenyltrichloroethane) and BHC (benzoate hexachloride) used on a large area (Zhu \& Cheng, 2013) along with different insecticides related to organophosphates, carbamates, pyrethroids, neonicotinoids, and insect growth regulators have been used since 1970s to up till now for the management of $N$. lugens (Gorman et al., 2008; Matsumura et al., 2008). However, thiamethoxam, chlorpyrifos, nitenpyram, and pymetrozine are more trusted pesticides for the management of $N$. lugens in China (Wang et al., 2013; Zhang et al., 2014). Due to the high fecundity of $N$. lugens, synthetic pesticides were used widely for its management (Su et al., 2013). This intense application of insecticides in paddy fields, induced a rapid insecticide resistance in $N$. lugens but also play an important role in the failure of different chemical insecticides (Nagata, 1985; Zhang et al., 
2014). N. lugens already developed resistance against organochlorines, organophosphates, carbamates, and pyrethroids, which are for major insecticidal groups (Matsumura et al., 2009; Wang et al., 2013). Comparatively, low-level resistance found in $N$. lugens against buprofezin (insect growth regulator) (Li, 2007; Zhuang et al., 2004). Many previous studies reported the resistance of $N$. lugens against different insecticides. In 2005 an outbreak of $N$. lugens was reported due to imidacloprid resistance (Wang et al., 2008). Intergroup cross resistance is also a cause of failure of whole insecticide group (Ausborn et al., 2005) There is a need for strict monitoring of insecticide resistance in N. lugens for better control (Min et al., 2014).

Neonicotinoids are an important group of pesticides all over the world due to their high efficacy and versatile range against different insect pests. Insects started to develop resistance against neonicotinoid insecticides (Jeschke et al., 2011). The first reported resistance was in 1996 when low resistance observed in whitefly against imidacloprid (Cahill et al., 1996). Up till now, according to SciFinder ${ }^{\circledR}$ 2014, American Chemical Society published more than 500 publications for neonicotinoid resistance and more than 300 cases of imidacloprid resistance reported Arthropod Pesticide Resistance Database (APRD) (Bass et al., 2015; University Michigan State, 2014). Most reported resistant insects are green peach aphid, Myzus persicae, the cotton aphid, Aphis gossypii, the rice brown planthopper, Nilaparvata lugens, houseflies, Musca domestica, Colorado potato beetle, Leptinotarsa decemlineata and glasshouse whitefly, Trialeurodes vaporariorum (Bass et al., 2015).

In whole life, insects deal with many toxic substances that can be natural as well as many agrochemicals like insecticides. This detoxification process is a key defensive mechanism for the insects for resistance or tolerance (Wu et al., 2011). Enzymatic activities can play an important role in understanding the susceptibility and tolerance or resistance against insecticide. The alternation in the level of detoxification enzymes is a common mechanism in response to the exposure of any stress of insects (Baker et al., 1998). Detoxification enzymes are typically involved in the metabolic process to act on the target site where toxic substance attacks in the insect body (Lin et al., 2015). The activity of enzymes in the detoxification process was observed higher in resistant species of insects as compared to susceptible ones, which is an important mechanism to confer the insecticide detoxification process (Denholm, 1992; Lu \& Gao, 2009). Previously reported literature stated that Glutathione-S-transferase (GST), carboxylesterases (CarEs), acetylcholinesterase (AChE), and others are the basic detoxification enzymes that involve in the metabolic detoxification of xenobiotic (Hafeez et al., 2019; Hu et al., 2014; Wang et al., 2013).

The present study aimed to assess the current status of insecticide resistance in $N$. lugens against neonicotinoids insecticides (imidacloprid, nitenpyram, thiamethoxam, and clothianidin). This study also aimed to determine how different enzymes act for the detoxification of these insecticides and their role in insecticide resistance under pesticide selection pressure.

\section{Materials and Methods}

\subsection{Insects}

The population of $N$. lugens collected from different locations of the paddy fields of Huazhong Agricultural University. This population raised under laboratory conditions for several generations without exposure to any insecticide. Population reared more than ten generations under laboratory conditions $\left(27 \pm 1^{\circ} \mathrm{C}, 70-80 \%\right.$ humidity and a 16:8 h L:D cycle) were used for experimentation. For experimentation, fourth instar nymphs of $N$. lugens used. The insecticide selection process, the toxicity of all the insecticides evaluated of all the generations, and a median lethal concentration $\left(\mathrm{LC}_{50}\right)$ and lethal concentration $\left(\mathrm{LC}_{90}\right)$ determined. This median lethal concentration used for a successive generation as a selected concentration.

\subsection{Insecticides}

Four insecticides used in this experiment imidacloprid, thiamethoxam, clothianidin, and nitenpyram. Technical grade insecticides dissolved in acetone for preparation of the stock solution, and then 6 to 7 concentrations increased in the geometric ratio were prepared in acetone. Hebei VeYong Bio-Chemical Co., Ltd supplied imidacloprid (96\%). Hubei Kangbaotai Fine-Chemicals Co., Ltd supplied thiamethoxam (95\%), clothianidin (96\%) and nitenpyram (95.8\%).

\subsection{Bioassay}

The topical application method (Khan et al., 2018) used in this experiment for toxicity determination bioassay. Progressive concentrations applied to the fourth instar nymphs of $N$. lugens. The test insects were placed in a glass tube and then immobilised by using $\mathrm{CO}_{2} .0 .5 \mu \mathrm{l}$ of test concentration applied on the ventral side of $N$. lugens with the help of a micro-applicator (Burkard, England). For each concentration, twenty individuals used in one replication, and four replications set up. Treated insects kept in glass jars containing rice seedlings and a 
mixture of nutrient water. These jars kept in climatic chambers with a temperature of $27 \pm 1{ }^{\circ} \mathrm{C}$ with a $16: 8 \mathrm{~h} \mathrm{~L}: \mathrm{D}$ photoperiod. Mortality data was taken after 24 hours.

\subsection{Resistance Selection}

Resistance selection performed by utilising the leaf dip method (Ali et al., 2019). Almost 20 rice seedlings were washed and assembled and kept into a $500 \mathrm{~mL}$ plastic jar after treatment with test concentration. Around 3000, $4^{\text {th }}$ instar nymphs treated from each generation during the resistance selection procedure. After five days of treatment, survivors were collected and moved to a pesticide-free jar with new rice seedlings for the successive generation. Two pesticides, one against which $N$. lugens was most susceptible, and one against which $N$. lugens was more resistant was taken and subjected for determination of detoxification enzyme activity.

\subsection{Pesticide Additive Bioassay}

Due to the high resistance ratio, imidacloprid and clothianidin were selected and subjected to synergistic bioassay. The $\mathrm{LC}_{50}$ imidacloprid $\left(2.74 \mathrm{mg}\right.$ a.i $\left.\mathrm{L}^{-1}\right)$ and clothianidin $\left(0.64 \mathrm{mg}\right.$ a.i. $\left.\mathrm{L}^{-1}\right)$ computed from susceptible strains $\left(\mathrm{F}_{0}\right)$ of $N$. lugens were mixed in $1: 1$ ratio. A $100 \mathrm{ml}$ solution formed. The pesticides were applied to susceptible $N$. lugens population, imidacloprid resistant strain and clothianidin resistant strain by the method mentioned above. The enzymatic analysis was also done at this stage to assess the enzymatic activity.

\subsection{Enzyme Activity Determination}

\subsubsection{P450 Activity}

The activity of cytochrome P450 assessed by ethoxycoumarin-O-dethylase (ECOD). $4^{\text {th }}$ instar nymphs of $N$. lugens, which exposed to pesticides, were grinded, and $0.3 \mathrm{~g}$ sample homogenised in $900 \mu 1$ mixture of $1.0 \mathrm{mM}$ dithiothreitol (DTT), 1.0 mM PMSF, 1.0 mM EDTA and 10\% glycerol (0.1M, pH 7.5). The mixing was done on Ice and then centrifuged at $4{ }^{\circ} \mathrm{C}, 10,000 \mathrm{RPM}$ for $15 \mathrm{~min}$. Enzyme reaction system includes $125 \mu \mathrm{l}$ of enzyme solution, Sodium phosphate buffer $365 \mu \mathrm{l}(0.1 \mathrm{M}, \mathrm{pH} 7.5)$, NADPH $10 \mu \mathrm{l}(10 \mathrm{mM})$ and 7-EC $5 \mu \mathrm{l}$ of $(40 \mathrm{mM})$. After mixing, the mixture incubated at $30{ }^{\circ} \mathrm{C}$ for $15 \mathrm{~min} .15 \%$ TCA (trichloroacetic acid) added (150 $\left.\mu \mathrm{l}\right)$ to sack the reaction. The whole mixture was centrifuged at $10000 \mathrm{RPM}$ for $2 \mathrm{~min}$ and collected. $40 \mu \mathrm{lof} 1.6 \mathrm{mM}(\mathrm{pH}$ 10.5) glycine- $\mathrm{NaOH}$ buffer was added. The optical density (OD) set at $34{ }^{\circ} \mathrm{C}$ with the help of Spark $10 \mathrm{M}$ multimode Microplate Reader (TECAN, CA, Switzerland) at an excitation wavelength of $358 \mathrm{~nm}$ (Slit $5 \mathrm{~nm}$ ) and an emission wavelength of $465 \mathrm{~nm}$. The enzyme source was diluted 200 times for protein analysis.

\subsubsection{GST Activity}

Insects were treated topically with micro-applicator, and after 24 hours alive, $N$. lugens nymphs were transferred into centrifuge tubes and immediately frozen by liquid nitrogen $\left(-80^{\circ} \mathrm{C}\right)$. The activity of GST enzyme was assessed by following the procedure as described by Khan (2019). GST determination Kit (SR No. A004) bought from Nanjing Jiancheng Bioengineering Institute, China. The kit was mixed, as instructed by the manufacturer. Each sample ground in $0.2 \mathrm{M}$ phosphate buffer $(\mathrm{pH}=7.0)$. Bio-Rad spectrophotometer used for the analysis of absorbance of light at $412 \mathrm{~nm}$ wavelength. Moreover, the protein level sample also determined by using the Bradford assay kit purchased from Beyotime, Shanghai, China, by using BSA (Bovine Serum Albumin) as a standard.

\subsubsection{Carboxylesterases (CarE) Activity}

The activity of CarE was assessed by following the procedure as described by Nawaz (2018). For the assessment of esterase activity, $200 \mu \mathrm{l}$ of assay mixture shifted into a 96-well-plate. This mixture was consisting of $2 \mu \mathrm{l}$ of $0.2 \mathrm{M}$ alpha naphthyl acetate and $10 \mu \mathrm{l}$ of enzyme solution diluted in $0.2 \mathrm{M}(\mathrm{pH}$ 7.2) sodium phosphate buffer. The incubation of the solution done for $15 \mathrm{~min}$ at $37{ }^{\circ} \mathrm{C}$, and the reaction halted by supplementing of colorimetric reagent fast blue RR salt. After this, at $600 \mathrm{~nm}$ wavelength, the absorbance was measured with the help of a Bio-Rad spectrophotometer.

\subsection{Statistical Analysis}

PoloPlus (LeOra Software 2002, Berkeley, CA) used for the estimation of $\mathrm{LC}_{50}$ and $\mathrm{LC}_{90}$ at $95 \%$ interval and slopes. The following formula used to compute the resistance ratio:

$$
\mathrm{RR}=\frac{\mathrm{LC}_{50} \text { of Resistant population }}{\mathrm{LC}_{50} \text { of Susceptible population }}
$$

One-way ANOVA was used to assess the mean difference in enzymatic activity analysis with three replications via the Tuckey's test at $\mathrm{P}=0.05$ and the correlation between $\mathrm{LC}_{50}$ and enzyme activity also computed by SPSS. Graphical work is done with the help of Sigmaplot 12.0. 


\section{Results}

\subsection{Mortality and Resistance Development}

Results (Table 1) showed that the $\mathrm{LC}_{50}$ of imidacloprid at $\mathrm{F}_{0}$ was $2.74 \mathrm{mg}$ a.i. $\mathrm{L}^{-1}$ and $\mathrm{LC}_{50}$ of $\mathrm{F}_{15}$ computed $323.17 \mathrm{mg}$ a.i. $\mathrm{L}^{-1}$, due to selection pressure after 15 generations from $\mathrm{F}_{0}$ and $\mathrm{F}_{15}$, the resistance ratio increased up to 118.07 -fold. Thiamethoxam also showed $1.01 \mathrm{mg}$ a.i. $\mathrm{L}^{-1} \mathrm{LC}_{50}$, while this $\mathrm{LC}_{50}$ reached up to $91.54 \mathrm{mg}$ a.i. $\mathrm{L}^{-1}$ after $\mathrm{F}_{15}$. The increase in resistance was about 90.37 -fold. The $\mathrm{LC}_{50}$ of $\mathrm{F} 0$ on $N$. lugnes treated with clothianidin was $0.64 \mathrm{mg}$ a.i. $\mathrm{L}^{-1}$, which reaches up to $139.18 \mathrm{mg}$ a.i. $\mathrm{L}^{-1}$ after $\mathrm{F}_{15}$ under pesticide selection pressure. The resistance increased up to 217.81-fold as compared to $\mathrm{LC}_{50}$. The $\mathrm{LC}_{50}$ of susceptible strain exposed to nitenpyram was $0.41 \mathrm{mg}$ a.i. $\mathrm{L}^{-1}$, which increased up to 34.09 -fold and showed $\mathrm{LC}_{50}$ of $13.94 \mathrm{mg}$ a.i. $\mathrm{L}^{-1}$ after 15 generations under selection pressures. The increase in $\mathrm{LC}_{50}$ of different pesticides in different generations also can be seen in Figure 1.

Table 1. $\mathrm{LC}_{50}$ and $\mathrm{LC}_{90}$ values (mg a.i. $\mathrm{L}^{-1}$ ) of Nilaparvata lugens obtained from exposure of different generations

\begin{tabular}{|c|c|c|c|c|c|c|c|c|}
\hline Pesticide & G & $\mathrm{LC}_{50}\left(\mathrm{mg}\right.$ a.i. $\left.\mathrm{L}^{-1}\right)$ & Limit (CL 95\%) & $\mathrm{LC}_{90}\left(\mathrm{mg}\right.$ a.i. $\left.\mathrm{L}^{-1}\right)$ & Limit (CL 95\%) & Slope & $\chi^{2}$ & $\mathbf{R R}$ \\
\hline \multirow{6}{*}{ 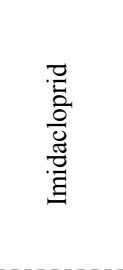 } & $\mathrm{F}_{0}$ & 2.74 & $2.26-3.26$ & 10.85 & $8.52-15.03$ & $2.142 \pm 0.206$ & 2.17 & 1 \\
\hline & $\mathrm{F}_{3}$ & 7.00 & $5.15-9.20$ & 34.22 & $23.31-62.58$ & $1.860 \pm 0.178$ & 4.17 & 2.56 \\
\hline & $\mathrm{F}_{6}$ & 36.73 & 25.91-50.99 & 226.69 & $138.84-522.95$ & $1.621 \pm 0.162$ & 4.78 & 13.42 \\
\hline & $\mathrm{F}_{9}$ & 75.42 & $60.20-93.67$ & 511.27 & $356.15-853.87$ & $1.542 \pm 0.158$ & 2.47 & 27.55 \\
\hline & $\mathrm{F}_{12}$ & 269.57 & 208.95-359.20 & 2753.02 & $1605.01-6310.58$ & $1.270 \pm 0.148$ & 1.15 & 98.49 \\
\hline & $\mathrm{F}_{15}$ & 323.17 & $248.48-441.45$ & 3432.60 & $1924.40-8460.50$ & $1.249 \pm 0.149$ & 0.68 & 118.07 \\
\hline \multirow{6}{*}{ 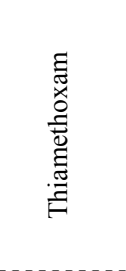 } & $\mathrm{F}_{0}$ & 1.01 & $0.63-1.37$ & 3.08 & $2.06-9.87$ & $2.652 \pm 0.335$ & 5.52 & 1 \\
\hline & $\mathrm{F}_{3}$ & 6.72 & $5.22-8.52$ & 48.27 & $31.39-95.73$ & $1.497 \pm 0.194$ & 1.03 & 6.64 \\
\hline & $\mathrm{F}_{6}$ & 17.51 & $13.88-22.28$ & 118.88 & $76.30-239.512$ & $1.541 \pm 0.194$ & 1.45 & 17.28 \\
\hline & $\mathrm{F}_{9}$ & 25.12 & $18.92-35.81$ & 279.04 & $140.66-954.37$ & $1.226 \pm 0.187$ & 0.35 & 24.79 \\
\hline & $\mathrm{F}_{12}$ & 69.19 & $50.56-108.97$ & 847.31 & $381.95-3764.07$ & $1.178 \pm 0.190$ & 0.16 & 68.30 \\
\hline & $\mathrm{F}_{15}$ & 91.55 & $64.70-158.70$ & 1122.80 & $472.05-5879.96$ & $1.177 \pm 0.194$ & 0.23 & 90.37 \\
\hline \multirow{6}{*}{ 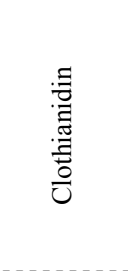 } & $\mathrm{F}_{0}$ & 0.64 & $0.49-0.80$ & 3.94 & $2.76-6.83$ & $1.621 \pm 0.201$ & 1.42 & 1 \\
\hline & $\mathrm{F}_{3}$ & 8.14 & $6.22-10.67$ & 74.47 & $43.65-183.55$ & $1.333 \pm 0.188$ & 0.06 & 12.74 \\
\hline & $\mathrm{F}_{6}$ & 21.90 & $16.71-29.99$ & 219.25 & $118.27-642.65$ & $1.281 \pm 0.188$ & 0.13 & 34.27 \\
\hline & $\mathrm{F}_{9}$ & 62.73 & $45.76-98.06$ & 844.26 & $373.02-3991.84$ & $1.135 \pm 0.187$ & 0.62 & 98.18 \\
\hline & $\mathrm{F}_{12}$ & 96.66 & 64.89-191.99 & 1724.10 & $596.76-15767.69$ & $1.024 \pm 0.189$ & 0.81 & 151.26 \\
\hline & $\mathrm{F}_{15}$ & 139.18 & $86.43-348.32$ & 2704.50 & $801.07-39285.51$ & $0.995 \pm 0.194$ & 0.21 & 217.81 \\
\hline \multirow{6}{*}{ 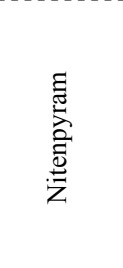 } & $\mathrm{F}_{0}$ & 0.41 & $0.33-0.51$ & 2.20 & $1.56-3.58$ & $1.756 \pm 0.190$ & 0.45 & 1 \\
\hline & $\mathrm{F}_{3}$ & 0.57 & $0.45-0.73$ & 3.87 & $2.49-7.59$ & $1.537 \pm 0.182$ & 1.00 & 1.39 \\
\hline & $\mathrm{F}_{6}$ & 1.67 & $1.30-2.28$ & 13.45 & $7.69-33.74$ & $1.416 \pm 0.189$ & 1.70 & 4.09 \\
\hline & $\mathrm{F}_{9}$ & 4.38 & $3.37-6.26$ & 33.53 & $18.35-93.34$ & $1.450 \pm 0.202$ & 0.82 & 10.72 \\
\hline & $\mathrm{F}_{12}$ & 8.34 & $5.42-18.32$ & 122.19 & $42.14-1114.93$ & $1.099 \pm 0.201$ & 1.81 & 20.40 \\
\hline & $\mathrm{F}_{15}$ & 13.94 & $10.05-23.32$ & 114.68 & $54.52-441.64$ & $1.400 \pm 0.215$ & 0.93 & 34.09 \\
\hline
\end{tabular}

Note. $\mathrm{G}=$ generations; $\mathrm{CL}=$ Critical limit; $\mathrm{RR}=$ Resistance Ratio. 


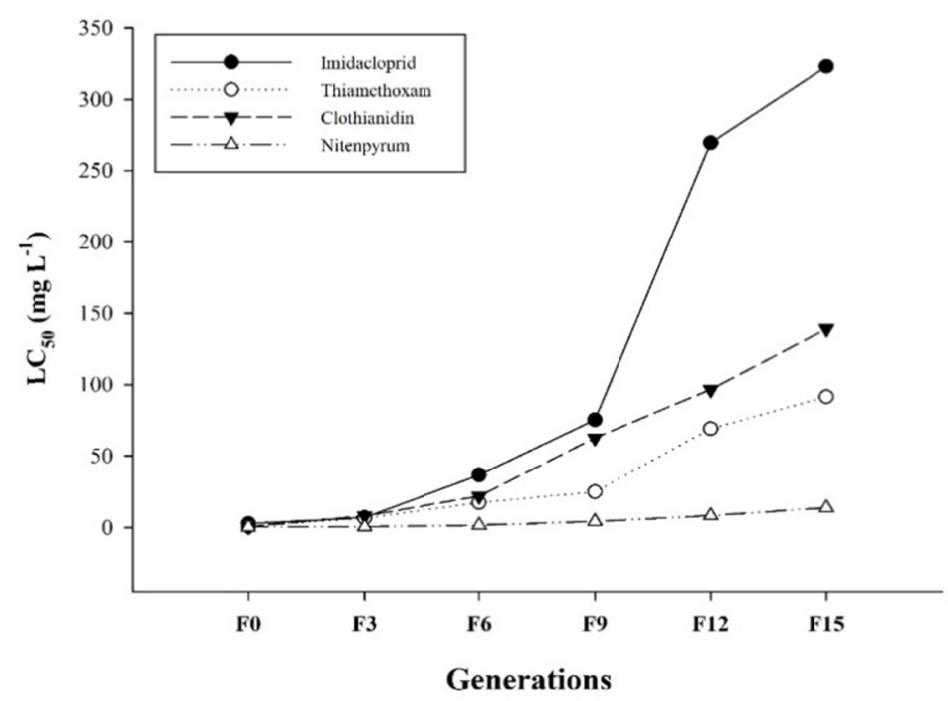

Figure 1. $\mathrm{LC}_{50}$ of different insecticide against different generations of brown planthopper

\subsection{Enzymes Activity}

Three detoxification enzymes cytochrome P450, esterase, and GST used to assess the activity of these enzymes in different generations exposed to thiamethoxam. Results showed that $\mathrm{P} 450$ activity increased significantly $(\mathrm{F}=$ $3.59, \mathrm{P}<0.05, \mathrm{df}=5$ ) higher in $\mathrm{F}_{15}$, where the value of $\mathrm{LC}_{50}$ was also higher than successive generations. The increase in esterase enzyme activity was also significant in $\mathrm{F}_{15}$ as compared to that in previous generations ( $\mathrm{F}=$ $21.88, \mathrm{P}<0.001, \mathrm{df}=5)$. GST enzyme was observed significantly higher from $\mathrm{F}_{0}$ to $\mathrm{F}_{15}(\mathrm{~F}=11.00, \mathrm{P}<0.001$, df $=5$ ) (Figures 2A, 2B, and 2C). When samples of insects exposed to clothianidin subjected for enzymatic analysis results showed that as the generations pass detoxification enzyme concentration was also increased under pesticide selection pressure as compared to that in $\mathrm{F}_{0}$ esterase $(\mathrm{F}=47.1, \mathrm{P}<0.01, \mathrm{df}=5)$ and GST $(\mathrm{F}=11.90, \mathrm{P}$ $<0.01, \mathrm{df}=5)$, but there was a non-significant increase in $\mathrm{P} 450$ activity $(\mathrm{F}=0.71, \mathrm{P}>0.05, \mathrm{df}=5)$ was observed generation to generation (Figures 2D, 2E, and 2F). 

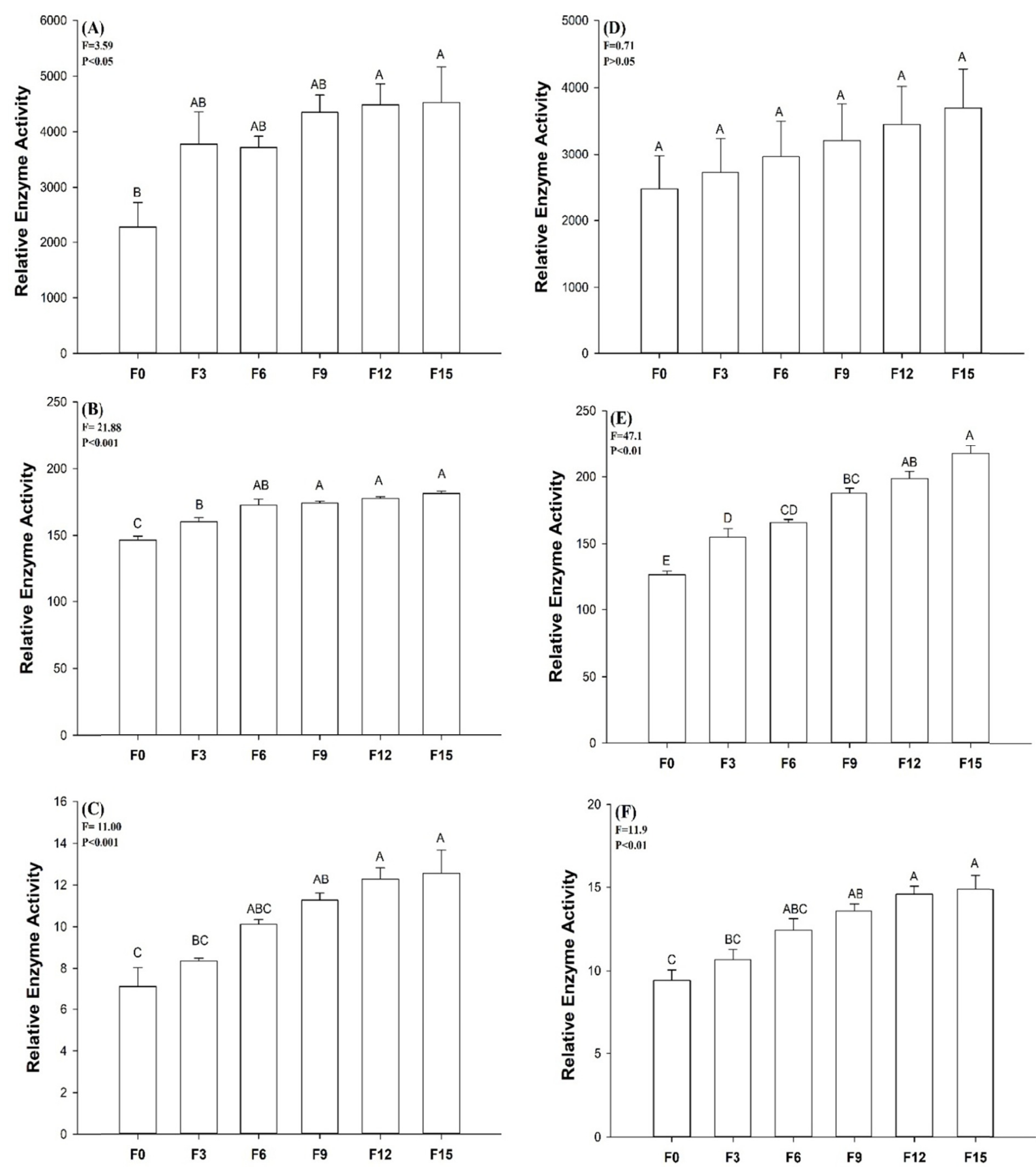

Figure 2. Comparison of enzyme activity of P450 (A,D), Esterase (B,E), and GST(C,F) enzymes in $F_{0}$ to $F_{15}$ under the selection pressure of imidacloprid (A, B and C) and clothianidin (D, E and F). The bars are showing the mean value of three replications. Error bars are showing Standard error of the mean. Lettering on bar showing a significant difference in treatments and similar lettering showed no-significant difference computed with $\mathrm{P}=0.05$

\subsection{Correlation Between LC50 and Enzyme Activity}

Analysis of correlation of enzyme activity and $\mathrm{LC}_{50}$ of imidacloprid showed that esterase and GST enzyme activity increases as the $\mathrm{LC}_{50}$ increases, while the activity of cytochrome $\mathrm{P} 450$ has no significant correlation. The correlation between cytochrome P450, esterase and GST enzyme activity was significantly increased as the $\mathrm{LC}_{50}$ of increases (Tables 2 and 3). 
Table 2. Correlation between $\mathrm{LC}_{50}$ of imidacloprid and detoxification enzymes activity

\begin{tabular}{|c|c|c|c|c|c|}
\hline \multicolumn{6}{|c|}{ Correlations Imidacloprid } \\
\hline & & $\mathrm{LC}_{50}$ & P450 & Esterase & GST \\
\hline \multirow{3}{*}{$\mathrm{LC}_{50}$} & Pearson Correlation & 1 & 0.690 & $0.882^{*}$ & $0.860^{*}$ \\
\hline & Sig. (2-tailed) & - & 0.129 & 0.020 & 0.028 \\
\hline & $\mathrm{N}$ & 6 & 6 & 6 & 6 \\
\hline \multirow{3}{*}{$\mathrm{P} 450$} & Pearson Correlation & 0.690 & 1 & $0.926^{* *^{*}}$ & $0.907^{*}$ \\
\hline & Sig. (2-tailed) & .129 & - & 0.008 & 0.012 \\
\hline & $\mathrm{N}$ & 6 & 6 & 6 & 6 \\
\hline \multirow{3}{*}{ Esterase } & Pearson Correlation & $0.882^{*}$ & $0.926^{* *}$ & 1 & $0.979^{\text {* }}$ \\
\hline & Sig. (2-tailed) & 0.020 & 0.008 & - & 0.001 \\
\hline & $\mathrm{N}$ & 6 & 6 & 6 & 6 \\
\hline \multirow{3}{*}{ GST } & Pearson Correlation & $0.860^{*}$ & $0.907^{*}$ & $0.979^{* *}$ & 1 \\
\hline & Sig. (2-tailed) & 0.028 & 0.012 & 0.001 & - \\
\hline & $\mathrm{N}$ & 6 & 6 & 6 & 6 \\
\hline
\end{tabular}

Note. ${ }^{*}$ Correlation is significant at the 0.05 level; $* *$ Correlation is significant at the 0.01 level (2-tailed).

Table 3. Correlation between $\mathrm{LC}_{50}$ of clothianidin and detoxification enzymes activity

\begin{tabular}{|c|c|c|c|c|c|}
\hline \multicolumn{6}{|c|}{ Correlations Clothianidin } \\
\hline & & $\mathrm{LC}_{50}$ & $\mathrm{P} 450$ & Esterase & GST \\
\hline \multirow{3}{*}{$\mathrm{LC}_{50}$} & Pearson Correlation & 1 & $0.971^{* *}$ & $0.823^{*}$ & $0.917^{*}$ \\
\hline & Sig. (2-tailed) & - & 0.001 & 0.044 & 0.010 \\
\hline & $\mathrm{N}$ & 6 & 6 & 6 & 6 \\
\hline \multirow{3}{*}{ P450 } & Pearson Correlation & $0.971 * *$ & 1 & $0.934^{* *}$ & $0.982 * *$ \\
\hline & Sig. (2-tailed) & 0.001 & - & 0.006 & 0.000 \\
\hline & $\mathrm{N}$ & 6 & 6 & 6 & 6 \\
\hline \multirow{3}{*}{ Esterase } & Pearson Correlation & $0.823^{*}$ & $0.934 * *$ & 1 & $0.967 * *$ \\
\hline & Sig. (2-tailed) & 0.044 & 0.006 & - & 0.002 \\
\hline & $\mathrm{N}$ & 6 & 6 & 6 & 6 \\
\hline \multirow{3}{*}{ GST } & Pearson Correlation & $0.917^{*}$ & $0.982 * *$ & $0.967 * *$ & 1 \\
\hline & Sig. (2-tailed) & 0.010 & 0.000 & 0.002 & - \\
\hline & $\mathrm{N}$ & 6 & 6 & 6 & 6 \\
\hline
\end{tabular}

Note. ${ }^{*}$ Correlation is significant at the 0.05 level; $* *$ Correlation is significant at the 0.01 level (2-tailed).

\subsection{Pesticide Additive Bioassay}

For testing the additive effect of these pesticides, the mixture of imidacloprid and clothianidin tested against $\mathrm{F}_{15}$ resistant strain. Results in (Figure 3) showed that the imidacloprid resistance strain (IRS) and clothianidin resistant strain (CRS) exerted $68.33 \pm 5.69 \%$ and $65.00 \pm 5.69 \%$ mortality. The exerted mortality has no significant difference as compared to that in control (susceptible strain). These results showed that the resistant strains still showed high susceptibility to different pesticide combinations. The enzymatic analysis showed that P450, esterase and GST enzyme activity in CRS and IRS was non-significantly varying with control, which revealed that the combination of pesticide has an additive effect on resistant populations of $N$. lugens (Figure 4). 


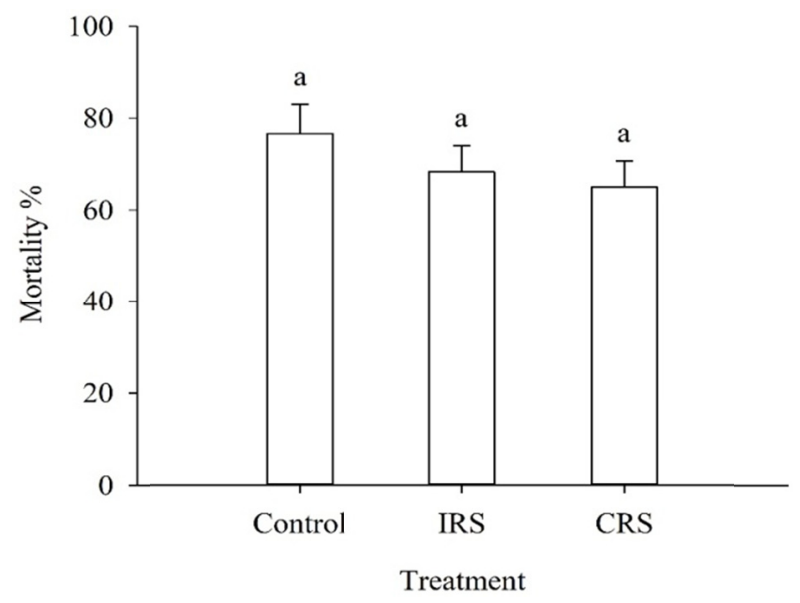

Figure 3. Percent mortality of control (susceptible strain), imidacloprid resistant strain (IRS; $F_{15}$ ), and clothianidin resistant strain $\left(\mathrm{CRS} ; \mathrm{F}_{15}\right)$, exposed to the mixture (1:1) to of imidacloprid and clothianidin. Bars are showing the mean percent mortality of 4 replicates; deviation bars are showing standard error of the mean at $\mathrm{P}=$ 0.05. Lettering on bar showing a significant difference in treatments and similar lettering showed no-significant difference computed at $\mathrm{P}=0.05$
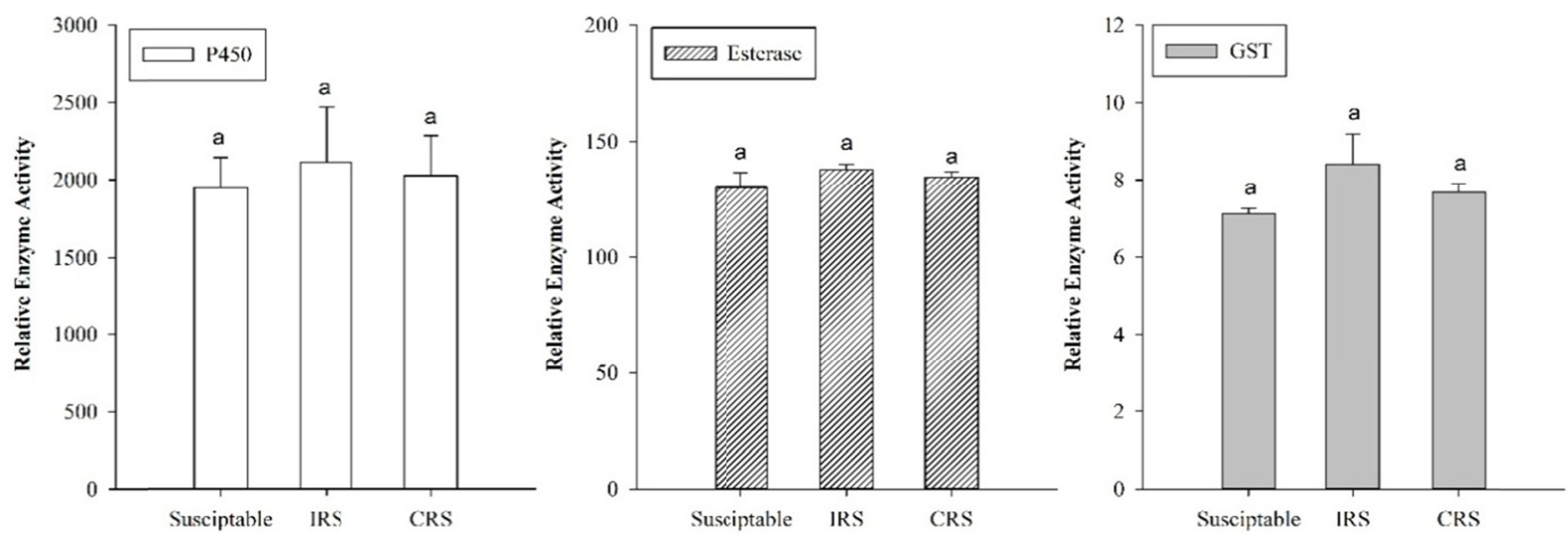

Figure 4. The enzymatic activity of control (susceptible strain), imidacloprid resistant strain (IRS; $F_{15}$ ), and clothianidin resistant strain $\left(\mathrm{CRS} ; \mathrm{F}_{15}\right)$ exposed to the mixture (1:1) to of imidacloprid and clothianidin. Bars are showing the mean enzymatic activity of 3 replicates; deviation bars are showing standard error of the mean at $\mathrm{P}$ $=0.05$. Lettering on bar showing a significant difference in treatments and similar lettering showed no-significant difference computed at $\mathrm{P}=0.05$

\section{Discussion}

Nilaparavata lugens is an economically important and a notorious pest of paddy (Oryza sativa L.) in China, Korea, and other eastern and south-eastern Asian countries (Li et al., 2018; Matsumura et al., 2008; Min et al., 2014). Synthetic insecticides have become one of the primary chemical control agents against this pest due to its high fecundity and long-distance migratory behaviour (Heong et al., 2015; Li et al., 2018; Zhang et al., 2017). Neonicotinoids are among the most widely used insecticides. However, intensive and repetitive use of these chemicals has led to the rapid development of resistance in $N$. lugens (Wang et al., 2008). The nicotinic acetylcholine receptors (nAChRs) in the insect central nervous system are the primary target for neonicotinoid insecticides, including imidacloprid (Bai et al., 1991; Schroeder \& Flattum, 1984). After the research from 1982 to 1987 , first resistance monitoring was done in Korea, where the examination of different field strains showed resistance against organophosphates, carbamates, and pyrethroids ranged from 1.1 to $6.9,1.0$ to 31.1 , and 0.9 to 6.0 fold, respectively (Yoo et al., 1997). However, in the early 1990s, imidacloprid was introduced in China and became a dominant chemical due to its relatively fast and systemic action against sucking pests (Sun et al., 2018). The development of a high level of resistance to imidacloprid in planthopper observed in many field populations in 2005 (Liu \& Han, 2006). In the present study, the field population of $N$. lugens maintained high resistance to 
imidacloprid. Results showed that due to continuous exposure of imidacloprid, thiamethoxam, clothianidin and nitenpyram for 15 generations, the resistance increased 118.07-fold, 90.37-fold, 217.81-fold and 34.09-fold, respectively. Gorman et al. (2008) studied the resistance development in N. lugens in 2005 and 2006 and reported a 100-fold increase in imidacloprid resistance in $N$. lugens. Jin et al. (2019) exposed $N$. lugens to clothianidin for 13 generations and reported the increase of resistance up to 174.33 -fold. (Sun et al., 2018) reported 26.5-fold increase in resistance due to selection pressure under thiamethoxam. The resistance levels of $N$. lugens against thiamethoxam (RR 25.9-159.2) rapidly increased in the period 2012-2014, a phenomenon similar to what had observed in the paddy field populations of N. lugens in China from 2011 to 2012 (Zhang et al., 2014) with moderate to high levels of resistance in Korea observed in this pest (Min et al., 2014). Zhang et al. (2017) reported a 33.9-fold increase in resistance when $N$. lugens was exposed to nitenpyram. These all results fortified the findings of the current study that under selection pressure, the $N$. lugens developed resistance against neonicotinoids. The current study also showed that nitenpyram is more effective as compared to other insecticides because of less resistance development. Wang et al. (2008) confirmed these results that $N$. lugens developed less resistance against nitenpyram.

The main reason for the rapid resistance development in $N$. lugens against neonicotinoids is not only its extensive and intensive use but also the cross-resistance between neonicotinoid insecticides (Matsumura et al., 2014; Wang et al., 2009). Neonicotinoid cross-resistance was reported in Bemisia tabaci (Feng et al., 2010), Leptinotarsa decemlineata (Mota-Sanchez et al., 2006) and Trialeurodes vaporariorum (Longhurst et al., 2013). The cross-resistance occurred when two different insecticides are hitting the same target side and due to over and over exposure, the mutation occurs which induced resistance against other insecticides (Bass et al., 2015).

The study of resistance mechanisms in insects considered a prerequisite for developing resistance management strategies (Wu et al., 2010; Xu et al., 2014). Gene regulation is often the main cause of insecticide resistance, which increased the cytochrome P450, GST and esterase enzyme activity for detoxification (Heckel, 2012). Increased activity of these detoxification enzymes is the most common mechanism of resistance (Heckel, 2012). In this study, the results showed that for detoxification of imidacloprid P450, esterase and GST enzymes played important role. The activity of all the enzymes increases as the generation increased. We found that the activity of the detoxification enzymes (esterase and GST) were significantly correlated with the LC50 values of imidacloprid, indicating that these detoxification enzymes may be involved in the observed resistance of $N$. lugens to imidacloprid. Previous studies showed that for the detoxification of imidacloprid, esterase enzymes showed high activity as compared to GST enzymes (Li et al., 2018). Wen et al. (2009) reported that resistant $N$. lugens strain against imidacloprid after 25 generations have a high activity of esterase enzymes as compared to the parent generations. Zhang et al. (2016) also reported that among all the populations collected from different provinces of China, most resistance populations against imidacloprid showed the higher activity of detoxification enzymes. There have been a few reports that esterase appeared to be responsible for neonicotinoid insecticide resistance. However, previous studies have not demonstrated that glutathione-S-transferase plays a role in neonicotinoid insecticide resistance in insect species. Current study also showed that esterase and GST enzymes play important role to detoxify clothianidin. Previous studies have reported that GST and esterase play a significant role in the detoxifying strategies of pests (Han et al., 1998; Heckel, 2012; Hemingway et al., 2002; Vontas et al., 2000; Zhang et al., 2012). Current study showed that when mixture of imidacloprid and clothianidin tested the resulted mortality was more than $60 \%$ and enzymatic activity was not significantly different. Many researchers also reported that mixture of different pesticides can enhance the toxicity which can also be an effective method to deal with resistance. $\mathrm{LC}_{50}$ : $\mathrm{LC}_{50}$ ratio mixture can produce the synergistic or antagonistic effect (Khan et al., 2013). If different pesticides mixed, their toxicity is also enhanced to control the resistant strain of $P$. xylostella (Attique et al., 2006).

From the present study, it can be concluded that continuous exposure to a single insecticide for a long time can be a reason of resistance induction. In the present study, due to the long term exposure of neonicotinoid insecticides, $N$. lugens induced resistance. Resistance against any pesticide is due to the detoxification of enzymes. Esterase and GST enzymes are more important in detoxification of neonicotinoid insecticides as compared to P450. The combination of different pesticides can also play an important role do deal with resistant strains of insects.

\section{Acknowledgements}

All authors are declaring no conflict of interest. The funds not taken from any Government or Non-Government Agency. We like to say thank you to Ms. Cui Lina from Daqing Foreign Language School for her valuable suggestions for the improvement of the manuscript language. 


\section{Reference}

Ali, E., Mao, K., Liao, X., Jin, R., \& Li, J. (2019). Cross-resistance and biochemical characterization of buprofezin resistance in the white-backed planthopper, Sogatella furcifera (Horvath). Pesticide Biochemistry and Physiology, 158(April), 47-53. https://doi.org/10.1016/j.pestbp.2019.04.008

Attique, M. N. R., Khaliq, A., \& Sayyed, A. H. (2006). Could resistance to insecticides in Plutella xylostella (Lep., Plutellidae) be overcome by insecticide mixtures? Journal of Applied Entomology, 130(2), 122-127. https://doi.org/10.1111/j.1439-0418.2006.01035.x

Ausborn, J., Wolf, H., Mader, W., \& Kayser, H. (2005). The insecticide pymetrozine selectively affects chordotonal mechanoreceptors. Journal of Experimental Biology, 208(3), 4451-4466. https://doi.org/ $10.1242 /$ jeb.01917

Bai, D., Lummis, S. C. R., Leicht, W., Breer, H., \& Sattelle, D. B. (1991). Actions of imidacloprid and a related nitromethylene on cholinergic receptors of an identified insect motor neurone. Pesticide Science, 33(2), 197-204. https://doi.org/10.1002/ps.2780330208

Baker, J. E., Perez-Mendoza, J., Beeman, R. W., \& Throne, J. E. (1998). Fitness of a malathion-resistant strain of the parasitoid Anisopteromalus calandrae (Hymenoptera: Pteromalidae). Journal of Economic Entomology, 91(1), 50-55. https://doi.org/10.1093/jee/91.1.50

Bass, C., Denholm, I., Williamson, M. S., \& Nauen, R. (2015). The global status of insect resistance to neonicotinoid insecticides. Pesticide Biochemistry and Physiology, 121, 78-87. https://doi.org/10.1016/ j.pestbp.2015.04.004

Cahill, M., Gorman, K., Day, S., Denholm, I., Elbert, A., \& Nauen, R. (1996). Baseline determination and detection of resistance to imidacloprid in Bemisia tabaci (Homoptera: Aleyrodidae). Bulletin of Entomological Research, 86(4), 343-349. https://doi.org/10.1017/s000748530003491x

Denholm, I. (1992). Tactics for managing pesticide resistance in arthropods: Theory and practice. Annual Review of Entomology, 37(1), 91-112. https://doi.org/10.1146/annurev.ento.37.1.91

Feng, Y., Wu, Q., Wang, S., Chang, X., Xie, W., Xu, B., \& Zhang, Y. (2010). Cross-resistance study and biochemical mechanisms of thiamethoxam resistance in B-biotype Bemisia tabaci (Hemiptera: Aleyrodidae). Pest Management Science, 66(3), 313-318. https://doi.org/10.1002/ps.1877

Gorman, K., Liu, Z., Denholm, I., Brüggen, K. U., \& Nauen, R. (2008). Neonicotinoid resistance in rice brown planthopper, Nilaparvata lugens. Pest Management Science, 64(11), 1112-1125. https://doi.org/10.1002/ ps. 1635

Gorman, K., Liu, Z., Denholm, I., Bruggen, K.-U., \& Nauen, R. (2008). Neonicotinoid resistance in rice brown planthopper, Nilaparvata lugens. Pest Management Science, 64(11), 1122-1125. https://doi.org/ $10.1002 /$ ps. 1635

Hafeez, M., Liu, S., Jan, S., Ali, B., Shahid, M., Fernández-Grandon, G. M., ... Wang, M. (2019). Gossypol-induced fitness gain and increased resistance to deltamethrin in beet armyworm, Spodoptera exigua (Hübner). Pest Management Science, 75(3), 683-693. https://doi.org/10.1002/ps.5165

Han, Z., Moores, G. D., Denholm, I., \& Devonshire, A. L. (1998). Association between biochemical markers and insecticide resistance in the cotton aphid, Aphis gossypii glover. Pesticide Biochemistry and Physiology, 62(3), 64-71. https://doi.org/10.1006/pest.1998.2373

Heckel, D. G. (2012). Insecticide resistance after silent spring. Science, 337, 1612-1614. https://doi.org/10.1126/ science. 1226994

Hemingway, J., Field, L., \& Vontas, J. (2002). An overview of insecticide resistance. Science, 298(5591), 96-97. https://doi.org/10.1126/science.1078052

Heong, K. L., Wong, L., \& Reyes, J. H. D. (2015). Addressing planthopper threats to Asian rice farming and food security: Fixing insecticide misuse. Rice Planthoppers: Ecology, Management, Socio Economics and Policy (pp. 65-76). https://doi.org/10.1007/978-94-017-9535-7_3

Hu, Z. D., Feng, X., Lin, Q. S., Chen, H. Y., Li, Z. Y., Yin, F., .. Gao, X. W. (2014). Biochemical mechanism of chlorantraniliprole resistance in the diamondback moth, Plutella xylostella Linnaeus. Journal of Integrative Agriculture, 13(11), 2452-2459. https://doi.org/10.1016/S2095-3119(14)60748-6

Jeschke, P., Nauen, R., Schindler, M., \& Elbert, A. (2011). Overview of the status and global strategy for 
neonicotinoids. Journal of Agricultural and Food Chemistry, 59(7), 2897-2908. https://doi.org/10.1021/ jf101303g

Jin, R., Mao, K., Liao, X., Xu, P., Li, Z., Ali, E., ... Li, J. (2019). Overexpression of CYP6ER1 associated with clothianidin resistance in Nilaparvata lugens (Stål). Pesticide Biochemistry and Physiology, 154(October 2018), 39-45. https://doi.org/10.1016/j.pestbp.2018.12.008

Khan, H. A. A., Akram, W., Shad, S. A., \& Lee, J. J. (2013). Insecticide mixtures could enhance the toxicity of insecticides in a resistant dairy population of Musca domestica L. PLoS ONE, 8(4), 8-15. https://doi.org/10.1371/journal.pone.0060929

Khan, M. M. (2019). Risk assessment of emamectin benzoate and chlorantraniliprole for the rove beetle Paederus fuscipes, a general predator of the brown planthopper Nilaparavata lugens (Doctoral dessertation. Huazhong Agricultural University, China). https://doi.org/10.1016/j.ecoenv.2018.08.047

Khan, M. M., Nawaz, M., Hua, H., Cai, W., \& Zhao, J. (2018). Lethal and sublethal effects of emamectin benzoate on the rove beetle, Paederus fuscipes, a non-target predator of rice brown planthopper, Nilaparvata lugens. Ecotoxicology and Environmental Safety, 165, 19-24. https://doi.org/10.1016/j.ecoenv. 2018.08.047

Li, G., Wu, Y., Liu, Y., \& Chen, X. (2018). Insecticides resistance and detoxification enzymes activity changes in brown planthopper, Nilaparvata lugens in Guizhou Province. Acta Ecologica Sinica, 39(3), $234-241$. https://doi.org/10.1016/j.chnaes.2018.09.001

Li, W. H. (2007). Studies on the susceptibility of several kinds of insecticides and resistance to imidacloprid in brown planthopper, Nilaparvata lugens (Stål) (Homoptera: Delphacidae) (Master thesis, Nanjing Agricultural University, China).

Lin, T., Cai, Z., \& Wu, H. (2015). Transcriptome analysis of the Japanese pine sawyer beetle, Monochamus alternatus (Coleoptera: Cerambycidae) by high-throughput Illumina sequencing. Journal of Asia-Pacific Entomology, 18(3), 439-445. https://doi.org/10.1016/j.aspen.2015.04.011

Liu, Z., \& Han, Z. (2006). Fitness costs of laboratory-selected imidacloprid resistance in the brown planthopper, Nilaparvata lugens Stål. Pest Management Science, 62(3), 279-282. https://doi.org/10.1002/ps.1169

Longhurst, C., Babcock, J. M., Denholm, I., Gorman, K., Thomas, J. D., \& Sparks, T. C. (2013). Cross-resistance relationships of the sulfoximine insecticide sulfoxaflor with neonicotinoids and other insecticides in the whiteflies Bemisia tabaci and Trialeurodes vaporariorum. Pest Management Science, 69(7), 809-813. https://doi.org/10.1002/ps.3439

Lu, Y., \& Gao, X. (2009). Multiple mechanisms responsible for differential susceptibilities of Sitobion avenae (Fabricius) and Rhopalosiphum padi (Linnaeus) to pirimicarb. Bulletin of Entomological Research, 99(1), 611-617. https://doi.org/10.1017/S0007485309006725

Maholidy, F. I. (2019). Repellency of volatile compounds of plant essential oils to planthoppers and one leafhopper species on rice (Master thesis, Huazhong Agricultural University, China).

Matsumura, M., Sanada-Morimura, S., Otuka, A., Ohtsu, R., Sakumoto, S., Takeuchi, H., \& Satoh, M. (2014). Insecticide susceptibilities in populations of two rice planthoppers, Nilaparvata lugens and Sogatella furcifera, immigrating into Japan in the period 2005-2012. Pest Management Science, 70(4), 615-622. https://doi.org/10.1002/ps.3590

Matsumura, M., Takeuchi, H., Satoh, M., Morimura, S. S., Otuka, A., Watanabe, T., \& Thanh, D. V. (2009). Current status of insecticide resistance in rice planthoppers in Asia. In K. L. Heong \& B. Hardy (Eds.), Planthopper: New Threats to the Sustainability of Intensive Rice Production Systems in Asia (1st ed., pp. 233-245). International Rice Research Institute.

Matsumura, M., Takeuchi, H., Satoh, M., Sanada-Morimura, S., Otuka, A., Watanabe, T., \& Van Thanh, D. (2008). Species-specific insecticide resistance to imidacloprid and fipronil in the rice planthoppers Nilaparvata lugens and Sogatella furcifera in East and South-east Asia. Pest Management Science, 64(11), 1115-1121. https://doi.org/10.1002/ps.1641

Min, S., Lee, S. W., Choi, B. R., Lee, S. H., \& Kwon, D. H. (2014). Insecticide resistance monitoring and correlation analysis to select appropriate insecticides against Nilaparvata lugens (Stål), a migratory pest in Korea. Journal of Asia-Pacific Entomology, 17(4), 711-716. https://doi.org/10.1016/j.aspen.2014.07.005

Mota-Sanchez, D., Hollingworth, R. M., Grafius, E. J., \& Moyer, D. D. (2006). Resistance and cross-resistance 
to neonicotinoid insecticides and spinosad in the Colorado potato beetle, Leptinotarsa decemlineata (Say) (Coleoptera: Chrysomelidae). Pest Management Science, 62(1), 30-37. https://doi.org/10.1002/ps.1120

Nagata, T. (1985). Chemical control of the brown planthopper in Japan. Japan Agricultural Research Quarterly, $18,176-181$.

Schroeder, M. E., \& Flattum, R. F. (1984). The mode of action and neurotoxic properties of the nitromethylene heterocycle insecticides. Pesticide Biochemistry and Physiology, 22(2), 148-160. https://doi.org/10.1016/ 0048-3575(84)90084-1

Su, J., Wang, Z., Zhang, K., Tian, X., Yin, Y., Zhao, X., ... Gao, C. F. (2013). Status of insecticide resistance of the whitebacked planthopper, Sogatella furcifera (Hemiptera: Delphacidae). Florida Entomologist, 96(3), 948-956. https://doi.org/10.1653/024.096.0332

Sun, X., Gong, Y., Ali, S., \& Hou, M. (2018). Mechanisms of resistance to thiamethoxam and dinotefuran compared to imidacloprid in the brown planthopper: Roles of cytochrome P450 monooxygenase and a P450 gene CYP6ER1. Pesticide Biochemistry and Physiology, 150(June), 17-26. https://doi.org/10.1016/j.pestbp. 2018.06.014

University Michigan State. (2014). Arthropod pesticide resistance database. Retrieved from https://www. pesticideresistance.org

Vontas, J. G., Small, G. J., \& Hemingway, J. (2000). Comparison of esterase gene amplification, gene expression and esterase activity in insecticide susceptible and resistent strains of the brown planthopper, Nilaparvata lugens. Insect Molecular Biology, 9(6), 655-660. https://doi.org/10.1046/j.1365-2583.2000.00228.x

Wang, H. Y., Yang, Y., Su, J. Y., Shen, J. L., Gao, C. F., \& Zhu, Y. C. (2008). Assessment of the impact of insecticides on Anagrus nilaparvatae (Pang et Wang) (Hymenoptera: Mymanidae), an egg parasitoid of the rice planthopper, Nilaparvata lugens (Hemiptera: Delphacidae). Crop Protection, 27(3-5), 514-522. https://doi.org/10.1016/j.cropro.2007.08.004

Wang, P., Ning, Z. P., Zhang, S., Jiang, T., Tan, L. R., Dong, S., \& Gao, C. F. (2013). Resistance monitoring to conventional insecticides in brown planthopper, Nilaparvata lugens (Hemiptera: Delphacidae) in main rice growing regions in China. Chinese Journal of Rice Science, 27(2), 191-197.

Wang, X., Khakame, S. K., Ye, C., Yang, Y., \& Wu, Y. (2013). Characterisation of field-evolved resistance to chlorantraniliprole in the diamondback moth, Plutella xylostella, from China. Pest Management Science, 69(5), 661-665. https://doi.org/10.1002/ps.3422

Wang, Y, \& Wang, M. (2007). Factors affecting the outbreak and management tactics of brown planthopper in China recent years. Pesticide Science and Administration, 29, 49-54.

Wang, Y. H., Wu, S. G., Zhu, Y. C., Chen, J., Liu, F. Y., Zhao, X. P., .. Shen, J. L. (2009). Dynamics of imidacloprid resistance and cross-resistance in the brown planthopper, Nilaparvata lugens. Entomologia Experimentalis et Applicata, 131(1), 20-29. https://doi.org/10.1111/j.1570-7458.2009.00827.x

Wang, Y., Chen, J., Yu, C. Z., Ma, C., Huang, Y., \& Shen, J. (2008). Susceptibility to neonicotinoids and risk of resistance development in the brown planthopper, Nilaparvata lugens (Stål) (Homoptera: Delphacidae). Pest Management Science, 64(12), 1278-1284. https://doi.org/10.1002/ps.1629

Wen, Y., Liu, Z., Bao, H., \& Han, Z. (2009). Imidacloprid resistance and its mechanisms in field populations of brown planthopper, Nilaparvata lugens Stål in China. Pesticide Biochemistry and Physiology, 94(1), 36-42. https://doi.org/10.1016/j.pestbp.2009.02.009

Wu, S., Li, M., Tang, P. A., Felton, G. W., \& Wang, J. J. (2010). Cloning and characterization of acetylcholinesterase 1 genes from insecticide-resistant field populations of Liposcelis paeta Pearman (Psocoptera: Liposcelididae). Insect Biochemistry and Molecular Biology, 40(5), 415-424. https://doi.org/ 10.1016/j.ibmb.2010.04.001

Wu, S., Yang, Y., Yuan, G., Campbell, P. M., Teese, M. G., Russell, R. J., ... Wu, Y. (2011). Overexpressed esterases in a fenvalerate resistant strain of the cotton bollworm, Helicoverpa armigera. Insect Biochemistry and Molecular Biology, 41(1), 14-21. https://doi.org/10.1016/j.ibmb.2010.09.007

$\mathrm{Xu}, \mathrm{L} ., \mathrm{Wu}, \mathrm{M} .$, \& Han, Z. (2014). Biochemical and molecular characterisation and cross-resistance in field and laboratory chlorpyrifos-resistant strains of Laodelphax striatellus (Hemiptera: Delphacidae) from eastern China. Pest Management Science, 70(7), 1118-1129. https://doi.org/10.1002/ps.3657

Yoo, J. K., Park, H. M., Choi, B. R., Lee, S. G., \& Ahn, Y. J. (1997). Resistance monitoring and crossresistance 
of brown planthopper (Homoptera: Delphacidae), Nilaparvata lugens Stål in Korea. Korean Journal of Pesticide Science, 10, 41-47.

Zhang, X., Liao, X., Mao, K., Yang, P., Li, D., Alia, E., Wan, H., \& Li, J. (2017). The role of detoxifying enzymes in field-evolved resistance to nitenpyram in the brown planthopper Nilaparvata lugens in China. Crop Protection, 94, 106-114. https://doi.org/10.1016/j.cropro.2016.12.022

Zhang, X., Liao, X., Mao, K., Zhang, K., Wan, H., \& Li, J. (2016). Insecticide resistance monitoring and correlation analysis of insecticides in field populations of the brown planthopper Nilaparvata lugens (stål) in China 2012-2014. Pesticide Biochemistry and Physiology, 132, 13-20. https://doi.org/10.1016/ j.pestbp.2015.10.003

Zhang, X., Liu, X., Zhu, F., Li, J., You, H., \& Lu, P. (2014). Field evolution of insecticide resistance in the brown planthopper (Nilaparvata lugens Stål) in China. Crop Protection, 58, 61-66. https://doi.org/10.1016/ j.cropro.2013.12.026

Zhang, Y., Guo, H., Yang, Q., Li, S., Wang, L., Zhang, G., \& Fang, J. (2012). Overexpression of a P450 gene (CYP6CW1) in buprofezin-resistant Laodelphax striatellus (Fallén). Pesticide Biochemistry and Physiology, 104(3), 277-282. https://doi.org/10.1016/j.pestbp.2012.10.002

Zhu, Z. R., \& Cheng, J. A. (2013). Evolution and perspective of rice insect pest management strategy in China. Plant Protection, 39, 25-32.

Zhuang, Y. L., Shen, J. L., Dai, D. J., \& Zhou, W. J. (2004). Genetic analysis of resistance to buprofezin in the brown planthopper, Nilaparvata lugens (Stål) (Homoptera: Delphacidae). Acta Entomologica Sinica, 47, 749-753.

\section{Copyrights}

Copyright for this article is retained by the author(s), with first publication rights granted to the journal.

This is an open-access article distributed under the terms and conditions of the Creative Commons Attribution license (http://creativecommons.org/licenses/by/4.0/). 